\title{
Synthesis of Novel Coordination Polyurethanes
}

\author{
Lei Chen, Hao Xu, Yuping Zhu, Changzheng Yang, and Guang Shen*
}

\author{
Institute of Chemistry and Chemical Engineering, Nanjing University, Nanjing 210093, People's Republic of China \\ * Nanjing Automobile Institute, Nanjing 210037, People's Republic of China
}

(Received August 28, 1995)

\begin{abstract}
New coordination polyurethanes based on novel diols bis[ $N$-[[2-hydroxyphenyl]methylene $]$ hydroxylethyleneamino]-copper (II), cobalt (II), and nickel (II) were synthesized successfully. The products are elastomeric materials or powders. Similar to other polyurethane elastomers, the block copolymers synthesized in this paper exhibit two-phase microstructure and thermoplastic properties. Some samples show a Schlieren pattern under the polarizing optical microscope. The geometric structure of the ionic domains, which plays an important role in the properties of these materials, was determined by the nature of the metal ions.
\end{abstract}

KEY WORDS Polyurethane/Metal Ions / Synthesis / Coordination /

Macromolecule metal complexes have been studied extensively for several decades. This kind of material, which has many special chemical and physical properties, has attracted scientific and commercial attention. ${ }^{1,2}$

Polyurethane ionomers are well-known examples of ion-containing materials. ${ }^{3}$ Both carboxylated and sulfonated polyurethanes containing pendent ionic groups on the side of polyurethane backbone have been synthesized and studied at our laboratory. ${ }^{4,5}$ However, polyurethanes contain pendent groups and metal ions in the main chain were not studied to any great extent. Only a few reports of these polymers are known. ${ }^{6}$

Recent studies show that some metal complexes offer potentially mesogenic molecular structures. Some coordination polymers having liquid crystalline properties $^{7,8}$ have been achieved. In this paper, a new kind of polyurethane which is metal coordinated low molecular weight compounds, was synthesized and characterized.

\section{EXPERIMENTAL}

\section{Synthesis of Metallic Diols and Polyurethanes}

The synthesis of metallic diols and polyurethanes are summarized in Scheme 1.

In Scheme 1(Ia) stoichiometric ethanolamine was added to a solution of salicylaldehyde in $200 \mathrm{ml}$ of boiling absolute ethanol. Then stoichiometric sodium acetate in $20 \mathrm{ml}$ water was added to the above reaction system. Finally $100 \mathrm{ml}$ boiling ethanol solution containing a stoichiometric amount of metal acetate were added. The reaction mixture was kept boiling for $15 \mathrm{~min}$. The crystal precipitates from the solution after cooling and a second crystallization occurred from ethanol solution. The product was dried under an infra-red lamp for 24 hours.

The coordination polyurethanes were synthesized in $N, N^{\prime}$-dimethylformamide (DMF) under nitrogen atmosphere, using $0.5 \%$ by weight of stannous octoate catalyst. The poly(tetramethylene oxide) (PTMO $M_{\mathrm{n}}=980$ ) was first reacted with 4,4'-bis(isocyanatophenyl)ether (ODI) or 4,4'-bis(diisocyanatophenyl)methane (MDI) for $30 \mathrm{~min}$ at $70^{\circ} \mathrm{C}$. The coordination chain extender in DMF solution was then added to the reaction along with $0.5 \mathrm{wt} \%$ stannous octoate catalyst. To ensure comp- lete reaction, the mixture was maintained at $70^{\circ} \mathrm{C}$ for 4 hours. The product was recovered by precipitation in hot water and further washed with ethanol to remove any residual small molecule products. The films were cast from DMF in Teflon-casting dishes at atmosphere pressure, and were transferred to a vacuum oven at $60^{\circ} \mathrm{C}$ for a minimum of 48 hours to remove the residual solvent. The stoichiometric ratio of the samples is listed in Table I.

\section{Polymer Characterization}

Inductivity Coupled Plasma Quantometer (ICP) data was obtained on Jarrell-Ash $1100+2000$.

Ultra-violet Visible (UV-VIS) spectra were obtained by Shimadzu UV-240 recording spectrophotometer. The samples were in a solid state and the spectra were recorded in the range from $190-900 \mathrm{~nm}$.

Infrared spectra were recorded with a Nicolet 170SX FT-IR with dry air purging. One hundred scans at a resolution of $2 \mathrm{~cm}^{-1}$ were signal averaged before Fourier transformation. All spectra covered the range from $400-4000 \mathrm{~cm}^{-1}$.

Dynamic mechanical data were obtained at $110 \mathrm{~Hz}$ using a Rheovibron DDV-II apparatus. Samples were made by casting and the thickness depended on the temperature range studied. Samples were initially cooled to $-140^{\circ} \mathrm{C}$ and measurement mode at $2^{\circ} \mathrm{C}$ intervals with a heating rate of $2^{\circ} \mathrm{C} \min ^{-1}$.

Thermal analysis was carried out on a Perkin-Elmer DSC-2C interfaced with a Model 3600 data station using TADS software. Temperature and enthalpy calibration were carried out using indium and mercury as standards. A heating rate of $20 \mathrm{~K} \mathrm{~min}^{-1}$ and a cooling rate of $10 \mathrm{~K} \mathrm{~min}^{-1}$ under a $20 \mathrm{~mL} \mathrm{~min}^{-1}$ flow of dry air as the purge gas was used on the samples.

Optical texture was studied with a Leitz-350 polarizing optical microscope (POM) equipped with a Linkam hot stage and a polaroid camera. The polymer sample was placed between two glass slides and heated to the isotropic melt. The observation was carried out during heating and cooling.

Wide-angle X-ray Scattering (WAXD) patterns were obtained using monochromatic $\mathrm{Cu}-K_{\alpha}$ radiation $(\lambda=$ 


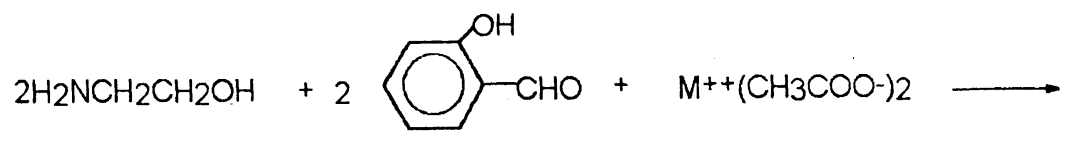

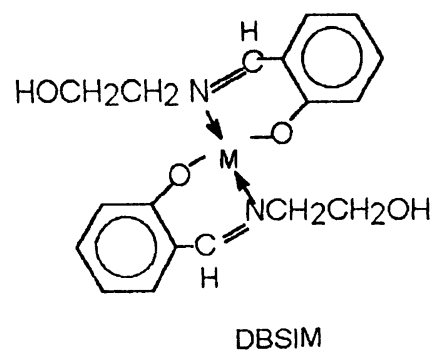

(Ia)

HO-R'-OH + OCN-R-NCO $\longrightarrow$ OCN-R-X-R'-X-R-NCO (II)

$\left(X=-\mathrm{HNCO}^{\mathrm{O}} \mathrm{O}-;\right) \quad\left(\mathrm{R}^{\prime}=-\left(\mathrm{CH}_{2} \mathrm{CH}_{2} \mathrm{CH}_{2} \mathrm{CH}_{2}\right)-;\right)$

$\left(\mathrm{R}=\left\langle\bigcirc \mathrm{CH}_{2}\langle\bigcirc:\langle\bigcirc\rangle\langle\bigcirc\rangle\right.\right.$,

(II) + (Ia)

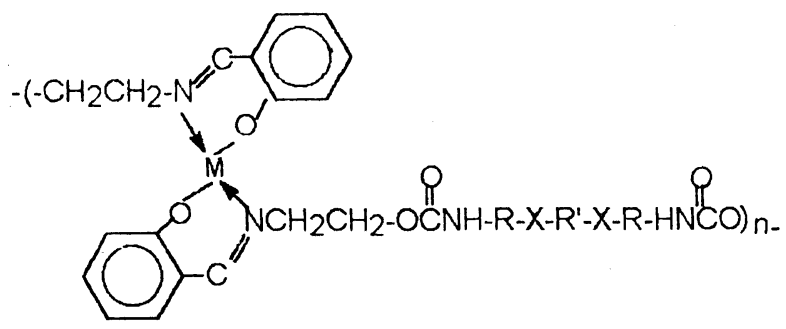

(Ib)

$\left(\mathrm{M}^{2+}=\mathrm{Cu}^{2+}, \mathrm{CO}^{2+}, \mathrm{Ni}^{2+}\right)$

Scheme 1. Synthesis of metallic diols (Ia) and coordination polyurethanes (Ib).

Table I. Compositions of samples synthesized

\begin{tabular}{|c|c|c|c|}
\hline Sample code & Diisocyanate & Cation & PTMO/Diisocyanate/DBSIM \\
\hline PMNil32 & MDI & $\mathrm{Ni}^{2+}$ & $1 / 3 / 2$ \\
\hline PMNil43 & MDI & $\mathrm{Ni}^{2+}$ & $1 / 4 / 3$ \\
\hline PONil32 & ODI & $\mathrm{Ni}^{2+}$ & $1 / 3 / 2$ \\
\hline POCu132 & ODI & $\mathrm{Cu}^{2+}$ & $1 / 3 / 2$ \\
\hline POCu143 & ODI & $\mathrm{Cu}^{2+}$ & $1 / 4 / 3$ \\
\hline POCu154 & ODI & $\mathrm{Cu}^{2+}$ & $1 / 5 / 4$ \\
\hline OCu11 & ODI & $\mathrm{Cu}^{2+}$ & $0 / 1 / 1$ \\
\hline PMCu132 & MDI & $\mathrm{Cu}^{2+}$ & $1 / 3 / 2$ \\
\hline PMCo132 & MDI & $\mathrm{Co}^{2+}$ & $1 / 3 / 2$ \\
\hline PMCo154 & ODI & $\mathrm{Co}^{2+}$ & $1 / 3 / 2$ \\
\hline
\end{tabular}

1.5418A) and a Nicolet Xentronics two-dimensional position sensitive and data system. Data were collected for $20 \mathrm{~min}$, and background scans of equivalent duration were subtracted to remove background scatter.

Uniaxial stress-strain measurements were made with a Shimadzu $100 \mathrm{KNE}$ at room temperature using a crosshead speed of $50 \mathrm{~mm} \mathrm{~min}^{-1}$. Samples were casted from cured films using an ASTM D1708 die.

\section{RESULTS AND DISCUSSION}

Coordination diols are powders, which are soluble in DMF but insoluble in water. Metal-containing polyurethanes were prepared by polyaddition reactions of these diols or mixtures of the diols and glycol with diisocyanates such as ODI or MDI. The products are elastomeric materials or powders which contain ionic links in the main chain. It should be noted that the coordination salts have catalytic activities for trimerization of NCO groups in DMF. ${ }^{9,10}$ When the concentra- 


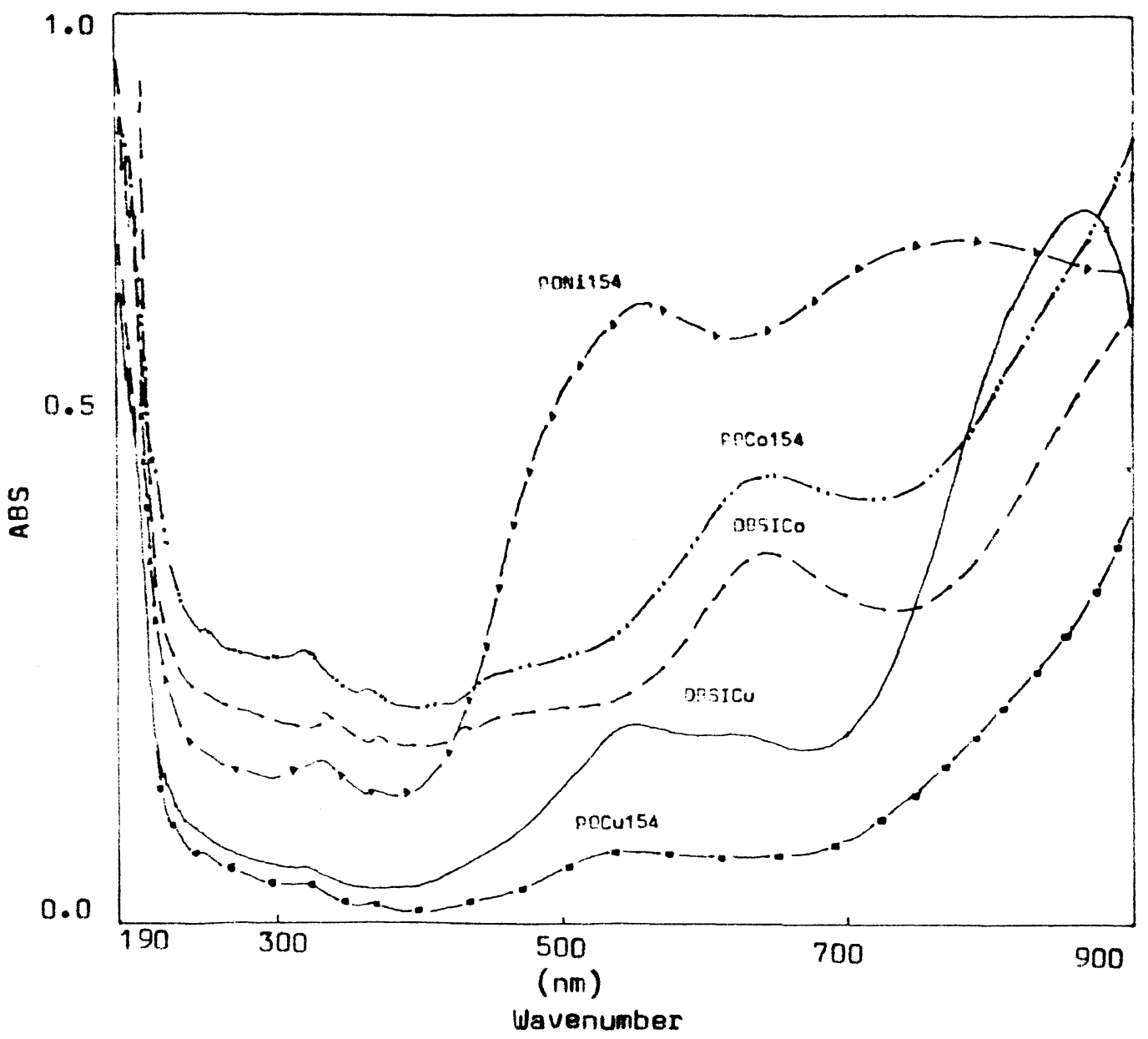

Figure 1. UV-VIS spectra of metal complexes.

tion of NCO groups in the reaction mixture is high, besides the urethane formation reaction, the trimerization of NCO groups is possible and gelation of the system is observed. Therefore, the concentration of the NCO group in the reaction mixture should be extremely low and the polyurethane should be prepared by the reaction of the salts with urethane prepolymers, that is, diisocyanate adducts of PTMO.

FT-IR absorption of DBSICu showed bands at $3228 \mathrm{~cm}^{-1}$ (OH stretching), $1640 \mathrm{~cm}^{-1}(\mathrm{C}=\mathrm{N}$ stretching), $1540 \mathrm{~cm}^{-1}\left(\mathrm{C}-\mathrm{N}\right.$ stretching) as well as $1350 \mathrm{~cm}^{-1}$ of phenyl ( $\widehat{\mathrm{O} Y})$ and $\left.760 \mathrm{~cm}^{-1}(\widehat{\mathrm{O}}]_{\mathrm{x}}^{\mathrm{x}}\right)$ proving the Schiff base structure. The metal content in diols was quantitatively determined by Inductivity Coupled Plasma quantometer analysis (ICP): $\mathrm{Cu}$ : found, $17.0 \%$; calcd, $16.2 \%$; $\mathrm{Co}$ : found, $14.8 \%$; calcd, $15.2 \%$; $\mathrm{Ni}$ : found, $14.9 \%$; calcd, $15.2 \%$. Melting points of the diols are 179 $180^{\circ} \mathrm{C}$ (DBSICu); $225-227^{\circ} \mathrm{C}$ (DBSICo); $235-238^{\circ} \mathrm{C}$ (DBSINi), which also prove the transition metal Schiff base diols are pure enough for the following reaction. The spectra of OCul1 showed the following characteristic absorption bands: $3295-3326 \mathrm{~cm}^{-1}$ (-NH stretching), $1710 \mathrm{~cm}^{-1}$ (urethane carbonyl stretching), $1621 \mathrm{~cm}^{-1}$ $\left(\mathrm{C}=\mathrm{N}\right.$ stretching), and $759 \mathrm{~cm}^{-1}\left(\widehat{\mathrm{O}}_{\mathrm{Y}}^{\mathrm{x}}\right)$. The bands at $1621 \mathrm{~cm}^{-1}$ and $759 \mathrm{~cm}^{-1}$, not found in the metal free analogues, indicated the presence of the chelat structure in the polyurethanes synthesized.

In UV-VIS spectra (Figure 1), the solid reflectance spectra of all metal complexes display strong absorption at $500-900 \mathrm{~nm}$ which are assigned to the $\mathrm{d}-\mathrm{d}$ transition. The maxima varied greatly with the nature of the transition metal ions. However, the UV-VIS spectra of polyurethane complexes were similar to the corresponding metal Schiff base diols. For samples based on $\mathrm{Co}^{2+}$, the reflectance maximum are at about $640 \mathrm{~nm}$ indicating an tetrahedral cobalt (II) complexes. The bands at $540 \mathrm{~nm}, 610 \mathrm{~nm}$, and $850 \mathrm{~nm}$ on the curves of DBSICu correspond to a square planar coordination structure. The polyurethane chains do not have profound influence on this geometric structure. Similarly, the reflectance spectra of PONi154 which exhibited two maxima at $550 \mathrm{~nm}$ and $780 \mathrm{~nm}$ also showed a square planar microstructure. The coordination distances of these complexes were $\mathrm{Cu}-\mathrm{O}, 1.89 \AA$; $\mathrm{Cu}-\mathrm{N}, 1.99 \AA$; Ni-O, $2.07 \AA$; $\mathrm{Ni}-\mathrm{N}, 1.97 \AA$; $\mathrm{Co}-\mathrm{O}, 1.96 \AA ; \mathrm{Co}-\mathrm{N}, 1.90 \AA .^{11}$

The coordination polyurethanes synthesized are composed of 'hard' and 'soft' segments except OCu11. Dynamic mechanical thermal analysis (DMTA) was used to explore the phase structures of these multiphase materials. The results are shown in Figure 2, and the glass transition temperatures taken as the maximal in loss tangent $(\tan \delta)$ are listed in Table II.

In Figure 2 the curves of tensile storage modules $\left(E^{\prime}\right)$ versus temperature exhibit a wide rubbery plateau extending from $-10^{\circ} \mathrm{C}$ to more than $100^{\circ} \mathrm{C}$, due to physical crosslinks of the materials by metal ions and hard segments. Since these coordination polyurethanes are linked by metal ions, these polymers have higher glass 


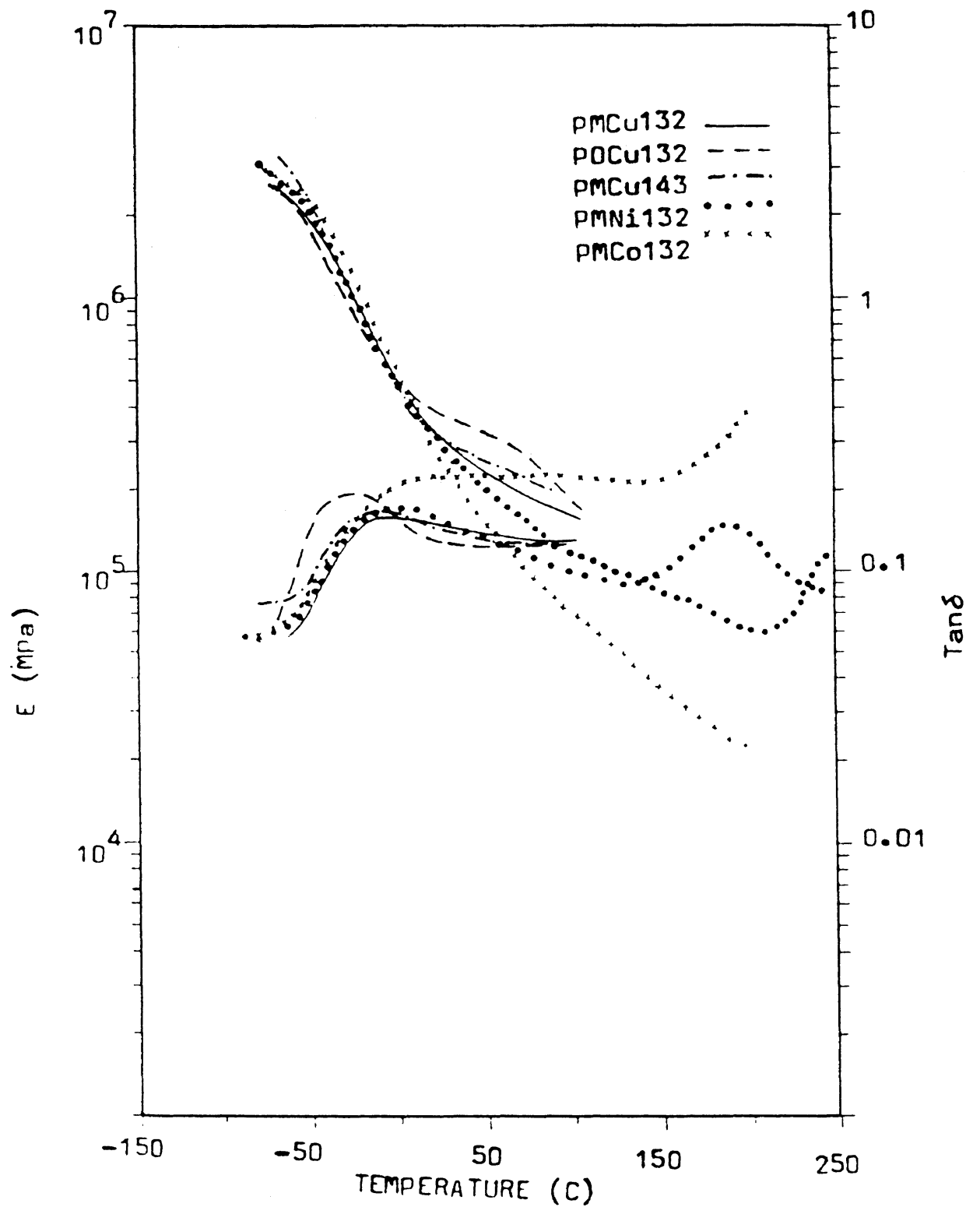

Figure 2. Dynamic mechanical analysis results.

Table II. Thermal transition data of samples

\begin{tabular}{lccccc}
\hline \multirow{2}{*}{ Sample code } & \multicolumn{2}{c}{ DSC endotherm } & & \multicolumn{2}{c}{ DMTA results } \\
\cline { 2 - 3 } \cline { 5 - 6 } & $T_{\mathrm{i}} / \mathrm{K}$ & $\Delta H / \mathrm{cal} \mathrm{g}^{-1}$ & & $T_{\mathrm{gs}_{\mathrm{s}}}$ & $T_{\mathrm{gh}_{\mathrm{h}}}$ \\
\hline DBSICo & 501.4 & 18.3 & & - & - \\
DBSICu & 453.2 & 30.01 & & - & - \\
DBSINi & 511.8 & - & & - & - \\
POCu154 & 434.3 & 4.64 & & - & - \\
POCu143 & - & - & & -7.7 & - \\
POCu132 & - & - & & -34.0 & - \\
PMCu154 & 424.0 & 2.76 & & - & - \\
PMCu132 & 436.3 & 3.64 & & -4.8 & - \\
Annealing & 446.2 & 10.13 & & -4.8 & - \\
PMCo132 & - & - & & 24.2 & $>189.0$ \\
PMNi132 & - & - & & 1.5 & 187.2 \\
\hline
\end{tabular}

transition temperatures and wider rubbery plateaus than those of polyurethane elastomers and polyurethane ionomers. ${ }^{8}$ Comparing the traces of the samples with different diisocyanates, we found the rubbery plateau of $\mathrm{PMCu} 132$ is lower than that of POCu132. This feature is due to that the microstructure based on MDI being less regular than the hard segment domain composed of ODI. ${ }^{12}$ As the length of the hard segment increases, there are more physical crosslinks at high temperature. Thus the rubbery plateau and transition temperature in the low temperature region of $\mathrm{PMCu} 143$ are higher than those of PMCu132. Besides the chemical composition of the urethane chain, the choice of metal ion is an important in the dynamic mechanical properties of the samples. In Figure 2, the storage modules of the samples with different central metal ions are in the following sequence $\mathrm{PMCu} 132>\mathrm{PMNi} 132>\mathrm{PMCo} 132$. However, $T_{\mathrm{g}}$ of the soft segment of these samples are in the reverse of the above (see Table II). This differs from that of the traditional polyurethane blockcopolymers. ${ }^{13}$ It is postulated that the dynamic properties of these transition metal Schiff base coordination polyurethanes was determined by the coordination structure.

Figure 3 shows the DSC traces of the samples. For DBSICu, DBSICo, and DBSINi, a distinct endothermic peak is found which corresponds to the isotropization 

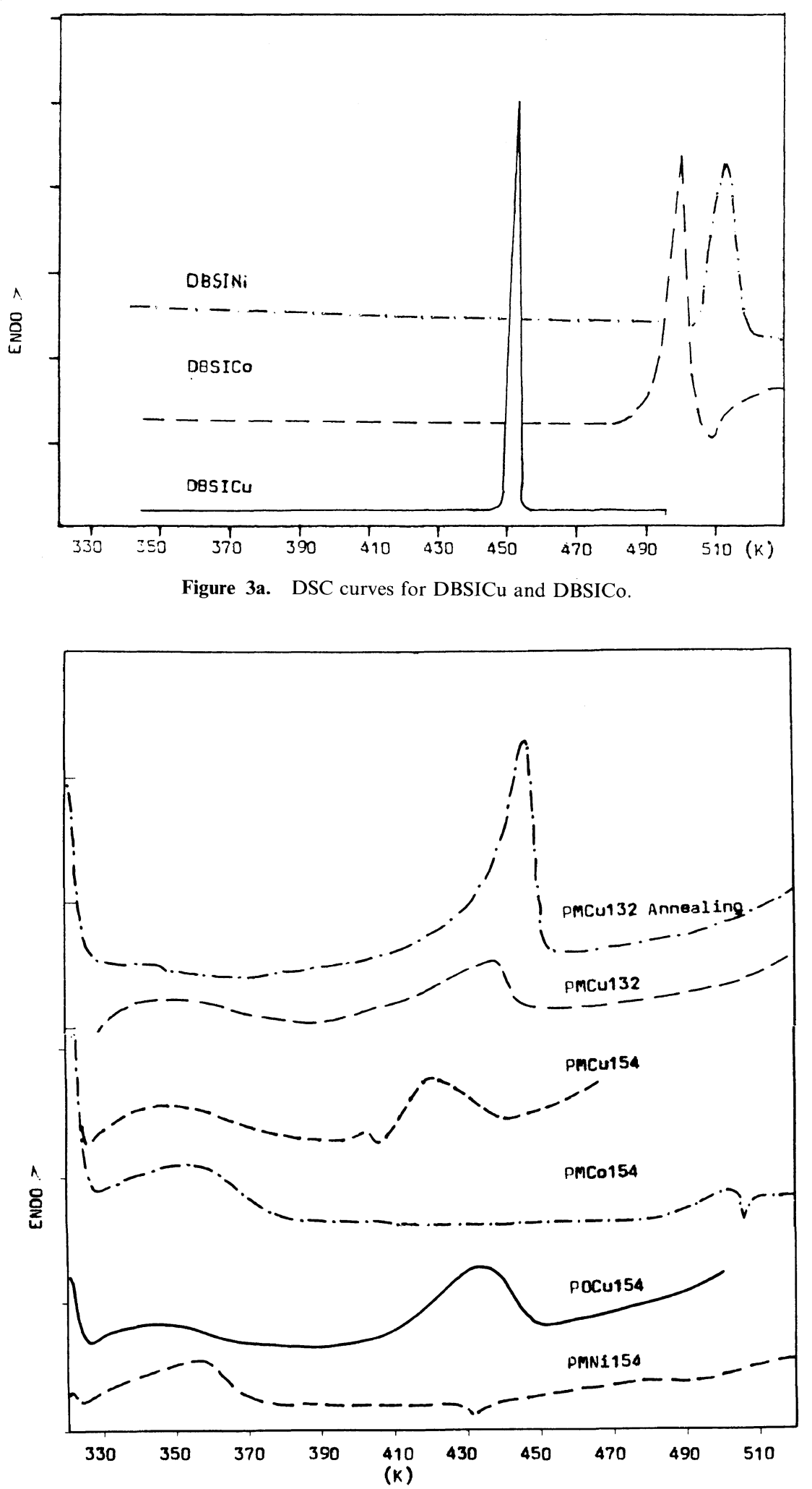

Figure 3b. DSC curves of samples.

temperature $\left(T_{\mathrm{i}}\right)$. Compared with coordination diols, two broad endotherms were found on the traces of polyurethane complexes. Polarizing optical microscopy observation indicated that the first endotherm near $350 \mathrm{~K}$ corresponds to a thermal transition in coordination polyurethane and the successive point is related to the mesophase isotropic phase transition. It is clear that the isotropization temperatures decrease with incorporating polyether soft segment. Eisenberg et al. ${ }^{14}$ show a decrease of the transition temperature with decrease of the number of repeating units in the hard segment. Furthermore, the broadening of endotherm in copolymers reflects the lack of uniformity of mesophase domain. This microstructure is due to the incorporation of PTMO soft segment or by the distribution of micromesophase size and the influence of the structure of the interfacial region. In addition, thermal treatment has remarkable influence on the crystallinity of the hard segment. Annealing of PMCu132 


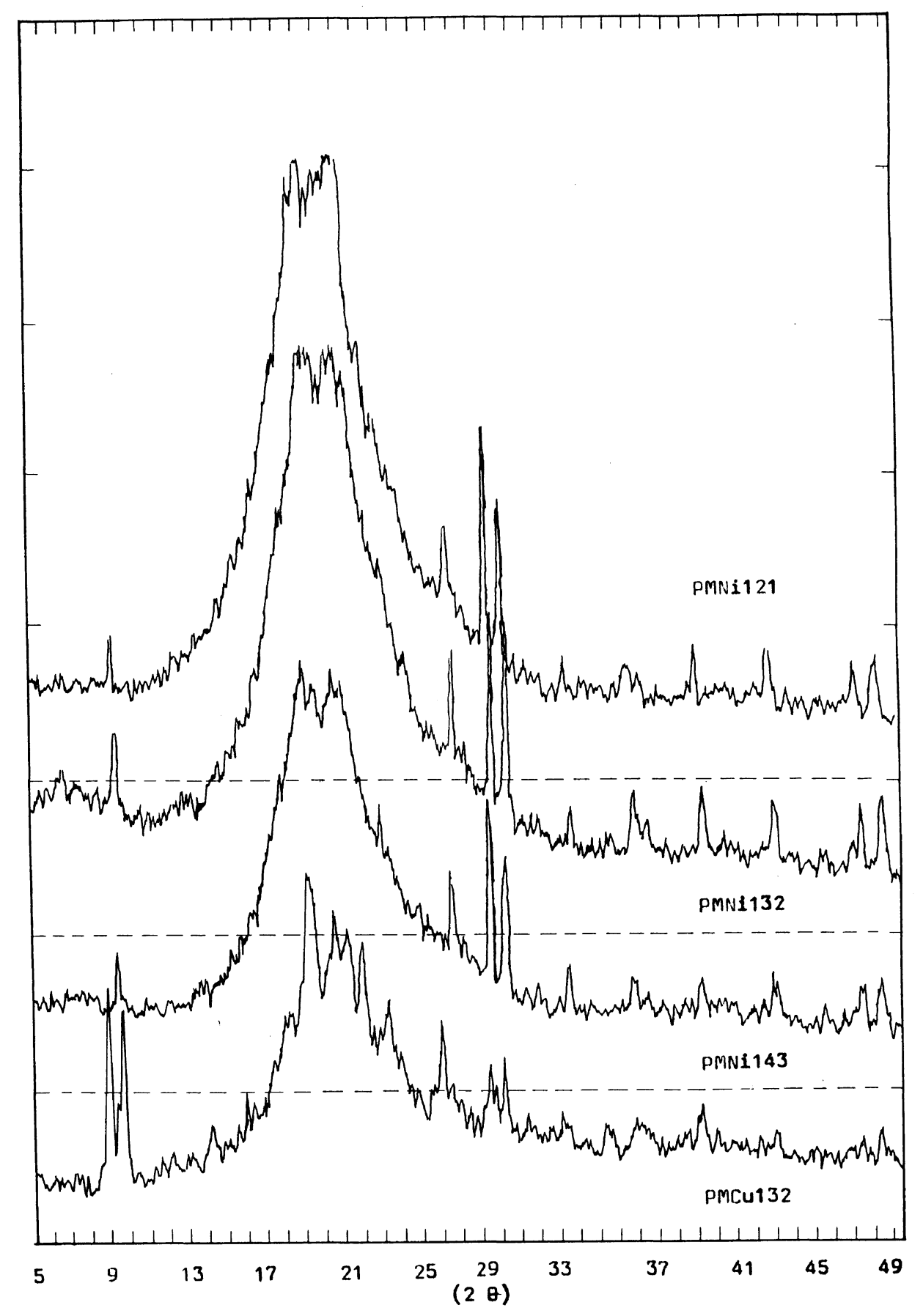

Figure 4. WAXD patterns of samples.

at $80^{\circ} \mathrm{C}$ narrows the endotherm transition peak in the high temperature region and yields a higher temperature mesophase, meanwhile the endotherm at $350 \mathrm{~K}$ vanished. This feature indicates that a more regular domain is achieved and the liquid crystalline structure can be preserved at room temperature as proved by POM in the following section. After quenching the sample to the room temperature, no endotherm appears on the curve. Annealing is required to observe the endothermic transition for the sample quenched to room temperature. ${ }^{15}$ The crystallinity of the mesophase was also determined by the type of diisocyanate and metal ions. In Figure 3, $\mathrm{Cu}^{2+}$ based samples showed clearer endotherm peaks compared with the other two samples. The regularity of the hard segment based on ODI is better than that of the sample consisting of MDI.

The crystal structures of these samples were also studied using wide angle X-ray diffraction (WAXD) (Figure 4) and polarizing optical microscope (Figure 5). It is reasonable to postulate that any crystallinity observed was due to the coordination diol with diisocyanates, because most of the polyurethanes have traces with amorphous scattering only. ${ }^{16}$ The crystallinity index of urethane hard segment was affected by the choice of metal cations. Clearly, PMCu132 trends to form a regular microstructure compared with PMNi132. This difference can be attributed to the extent of molecular fit within the hard segments. A more regular structure in the longer hard-segment domain was observed, compared to that in the shorter hard segment copolymer. 


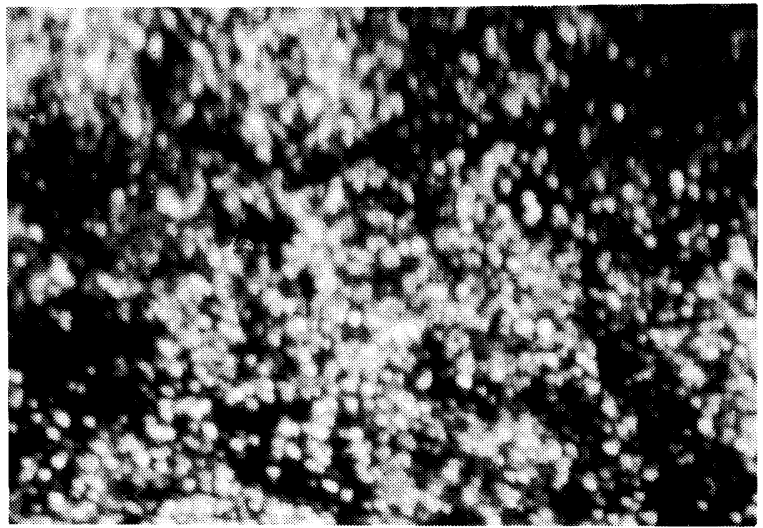

(a) $\mathrm{PMCu} 132$ at $150^{\circ} \mathrm{C}$

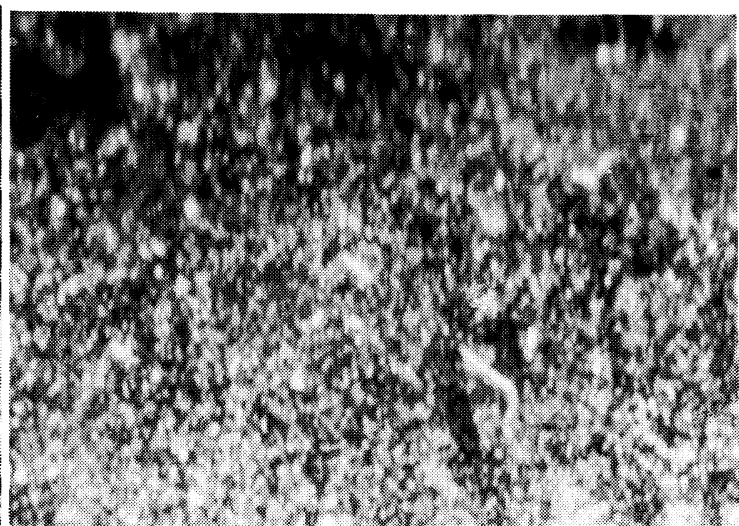

(c) PMCu132 at room temp (quenched from isotropic melt)

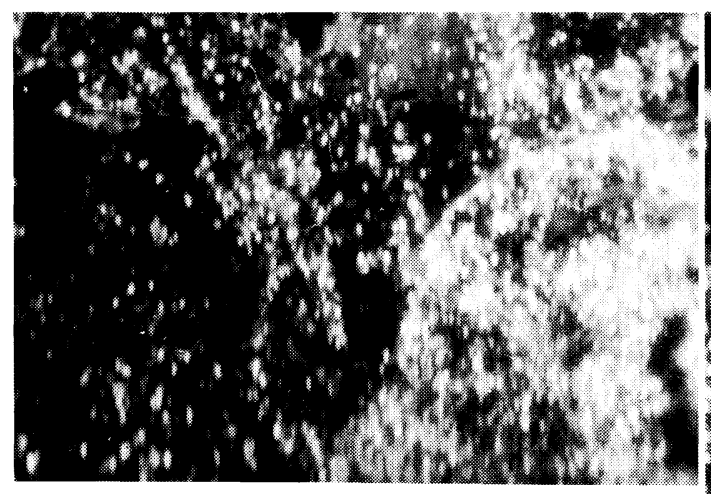

(b) DBSICo at room temp (quenched from isotropic melt)

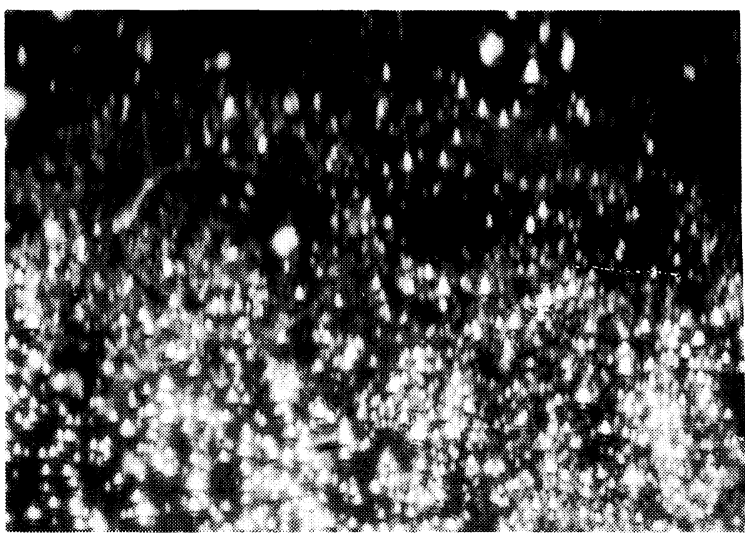

(d) PMCo154 at room temp (quenched from isotropic melt)

Figure 5. Polarizing optical microscope observation.

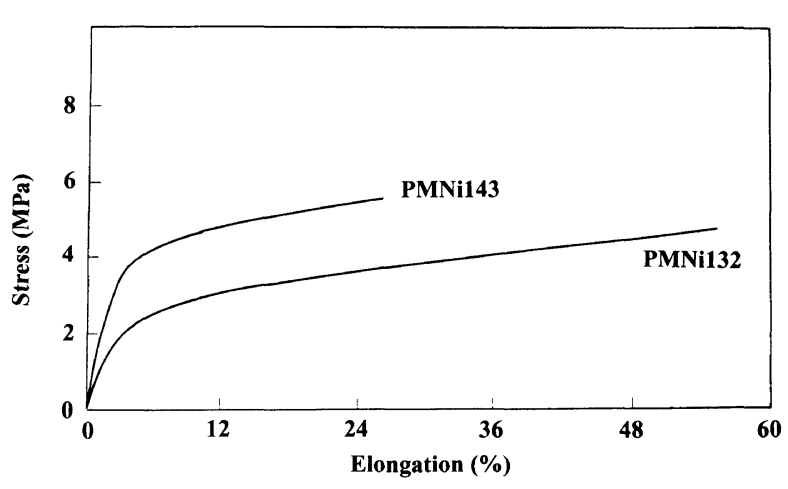

Figure 6. Stress-strain curves for PMNi143 and PMNi132.

Polarizing optical microscopy observation of DBSICo, PMCu132, and PMCo154, which were cooled from the isotropic melt points showed very dense Schlieren patterns. These liquid crystalline structure may be preserved at room temperature. A more detailed characterization of the crystal structure and liquid crystal properties of the samples will be reported in the other paper.

Finally, the mechanical properties of these block copolymers containing the metal ions on the main chain were studied. Most samples synthesized in this paper exhibit thermoplastic elastomer properties. Figure 6 shows the stress-strain curves for PMNi132 and
PMNi143. The modules of the polymers increase with the length of the hard segment, as was found by dynamic mechanical testing. Elongation at break decreases with hard segment content. Such behavior is similar to that of the ion free polyurethane block copolymer. ${ }^{17}$

\section{CONCLUSIONS}

A series of novel coordination polyurethanes connected by transition metal ions on the main chain was synthesized and studied. The products are elastomeric, glassy materials or powders. The coordination salts have catalytic activities for trimerization of NCO groups and the gelation of the system is observed besides the urethane formation reaction. All block copolymers in this study exhibit wider rubbery plateau than those of polyurethane elastomers and ionomers. The morphology of the samples was both determined by composition of the urethane chains and type of metal ion. It is observed that the geometric structures of the ionic domains based on $\mathrm{Cu}^{2+}$ and $\mathrm{Ni}^{2+}$ are in square planar state, while the complexes composed of $\mathrm{Co}^{2+}$ formed a tetrahedral microstructure. For $\mathrm{Cu}^{2+}$ and $\mathrm{Co}^{2+}$ based samples, a liquid crystalline structure was found under polarizing microscopy.

Acknowledgment. This work was supported by the Science Foundation of China. 


\section{REFERENCES}

1. J. E. Sheats, C. E. Carraher, Jr., and C. U. Pittman, Jr., Ed., "Metal-Containing Polymeric Systems," Plenum Press, New York, N.Y., 1985.

2. A. Eisenberg, Ed., "Ion-Containing Polymers," J. Polym. Sci., Polym. Symp., 45 (1974).

3. R. W. Rees and D. J. Vaughan, Polym. Prepr., Am. Chem. Soc., Div. Polym. Chem., 6, 287 (1965).

4. Y. S. Ding, R. A. Register, C. Z. Yang, and S. L. Cooper, Polymer, 30, 1024 (1989).

5. D. C. Lee, R. A. Register, C. Z. Yang, and S. L. Cooper, Macromolecules, 21, 998 (1988).

6. J. Economy, J. H. Mason, and C. Wohrer, J. Polym. Sci., A-1, 8, 2231 (1970).

7. K. Hanabusa, J. Higashi, T. Koyama, H. Shirai, N. Hojo, and H. Kurose, Makromol. Chem., 190, 1 (1989).
8. U. Caruso, A. Roviello, and A. Sirigu, Liq. Cryst., 7, 421 (1990).

9. H. Matsuda, J. Polym. Sci., Polym. Chem. Ed., 12, 2419 (1974).

10. H. Matsuda, J. Polym. Sci., Polym. Chem. Ed., 12, 469 (1974).

11. L. Chen, H. Hu, and C. Z. Yang, "Polymers for Advanced Technologies," Wiley, New York, N.Y., 1996, in press.

12. L. Chen, X. H. Yu, C. Z. Yang, and Y. P. Zhu, Polym. Mater. Sci. \& Technol., 5, 20 (1994).

13. L. Chen and X. H. Yu, Functional Polymers, 1, 19 (1991).

14. C. D. Eisenbach and H. Nefzger, "Multiphase Macromolecular Systems,” B. M. Culbertson, Ed., Plenum Press, New York, N.Y., 1989, p. 339.

15. W. Tang, R. J. Farris, and W. J. MacKnight, Macromolecules, 27, 2814 (1994).

16. C. Wilkes and C. S. Yusek, J. Macromol. Sci.-Phys., B7(1), 157 (1973).

17. S. L. Cooper and A. V. Tobolsky, J. Appl. Polym. Sci., 10, 1837 (1966). 